\title{
Sob rédeas curtas, de cabelos longos: reflexões sobre mulheres no hipismo
}

\author{
Vanessa Silva Pontes* \\ Erik Giuseppe Barbosa Pereira**
}

\begin{abstract}
Resumo: Esta revisão crítica descritiva busca refletir a inserção e a permanência da mulher no hipismo, iniciando uma discussão centrada na construção social das feminilidades dentro de uma modalidade elitizada e pouco explorada pelo campo das práticas corporais. A literatura abordada evidencia a existência de visões estereotipadas direcionadas às atletas quando o assunto é competição, família e emoção. O cavalo personifica-se como signo marcador e diferenciador das identidades de gênero inseridas nas práticas equestres, ainda que a modalidade se abstenha da desigualdade entre os sexos.
\end{abstract}

Palavras-chave: Hipismo. Mulheres. Feminilidades. História.

\section{INTRODUÇão}

O entusiasmo para a realização deste estudo surge da vivência da autoria como praticante amadora e entusiasta dos esportes a cavalo. Ainda criança, fascina-lhe o contato com um animal robusto, altivo e intimidador. Estar no controle de um quadrúpede que pode passar de 1,90m de garrote, pesar em torno de meia tonelada e ser aterrorizante à maioria de seus conhecidos se tornou um desafio. $\mathrm{O}$ medo, porém, nunca lhe foi um empecilho; o elitismo, sim.

\footnotetext{
'Escola de Educação Física e Desportos. Universidade Federal do Rio de Janeiro, RJ, Brasil. Email: vanessaflu@hotmail.com

"Escola de Educação Física e Desportos. Universidade Federal do Rio de Janeiro. Rio de Janeiro, RJ, Brasil. E-mail: egiuseppe@eefd.ufrj.br
} 
Mais tarde, novas nuances se articulam em sua mente: tratase de um esporte pouco explorado pela sua área de atuação, a Educação Física. Ainda que em processo de transformação, esta é uma ciência que tende a valorizar de tal forma os aspectos biocientíficos que chegou, até pouco tempo atrás, a desconsiderar os desportos equestres como exercícios físicos, alegando baixos gasto calórico e aumento da força muscular. $\mathrm{O}$ verdadeiro atleta seria o cavalo, o qual não seria objeto de estudo das Ciências do Esporte.

Instigada pelas questões de gênero, novas inquietações se avultam. Partindo da premissa de que o esforço físico não é fator determinante para um melhor desempenho, os esportes hípicos são os únicos em que homens e mulheres competem juntos, seguindo as mesmas regras. A partir dessa forte correlação entre esforço físico, esporte e, por que não, masculinidade, foi se delineando o escopo deste ensaio, que tem como objetivo refletir, sob a ótica das dimensões socioantropológicas, a inserção e permanência da mulher no contexto de um esporte dito de baixo esforço físico, mas de alto risco.

Consideramos a relevância deste ensaio justamente por ser um dos pioneiros a refletir a presença de hierarquias de gênero no hipismo brasileiro. $\mathrm{O}$ estado da arte das pesquisas relativas a essa temática nas práticas equestres revela-se como assaz atual e ainda restrito ao campo da Antropologia e Sociologia.

A literatura aponta que essas preocupações tiveram início no Brasil no ano de 1999 com Miriam Adelman, sendo complementadas por Luiz Fernando Rojo em 2007. O primeiro estudo desenvolvido por pesquisadores da Educação Física sobre o tema só foi realizado entre os anos de 2010 e 2011, por Ester Pereira, Carolina da Silva e Janice Mazo. Entendemos essa apoderação de um tema da ciência da qual fazemos parte por teóricos de outras áreas como reflexo da negação sofrida pelas atividades a cavalo a sua identidade esportiva.

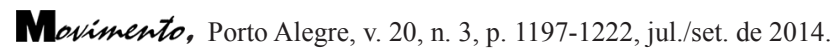


Metodologicamente, ancorada no campo de estudo do pósestruturalismo, esta revisão crítica de literatura é de caráter qualitativo e descritivo e se insere no paradigma fenomenológico. A nossa preocupação se debruça na maneira como os sujeitos da pesquisa, a saber, os cavaleiros e as amazonas, vivenciam um caso concreto do fenômeno investigado à luz da literatura e da vivência da autoria. Ferreira (1994, p.76) vem corroborar esses preceitos afirmando que um fenômeno "deve ser estudado a partir da experiência vivida pelo sujeito e não a partir de teorias e concepções adotadas a priori"'.

O alicerce da reflexão foi construído em quatro etapas: primeira, a seleção da bibliografia em revistas acadêmicas da Educação Física, Sociologia e Antropologia, tanto nacionais quanto internacionais, nas bases de dados Scielo, Scopus, Google Acadêmico, no banco de periódicos da CAPES e no Nuteses, além de livros e organizações sobre gênero na Educação Física e esporte, totalizando 320 obras catalogadas. Utilizamos como ferramentas de busca as palavras-chave "gênero", "hipismo" e "mulher". Em um segundo momento, realizamos uma leitura exploratória e, em seguida, uma analítica para ordenação e organização do material. Finalizando, de posse dos dados em forma de fichamentos, arquitetamos o corpus do estudo.

Em nível de organização, dividiremos esta reflexão da seguinte maneira: no item 2, denominado "O cavalo e as mulheres na Antiguidade", aprofundamos as questões histórico-culturais do uso desse animal e as atuações femininas e masculinas na Antiguidade. No ponto 3, em "O cavalo-atleta", descrevemos como se deu a transição do cavalo de mero animal de pastoreio a atleta. Na chamada 4, sob o título "Conceituando gênero", definimos os conceitos de gênero, masculinidades e feminilidades. Dando sequência, no tópico 5, explicitamos como a mulher tem o seu primeiro contato com o cavalo e com o esporte que se insurge, sendo este o tema de "Do lar às pistas, transpondo obstáculos". Na penúltima unidade, de número 6, designada "Essas mulheres... Esses cavalos... Por trás das cocheiras", investimos em uma

Movimento, Porto Alegre, v. 20, n. 3, p. 1197-1222, jul./set. de 2014. 
profunda análise crítica da literatura selecionada, com vistas a descortinar a participação feminina nos esportes hípicos. Nas "Considerações finais", delineamos o efeito cascata da inserção feminina nas práticas hípicas: era o cavalo inicialmente visto como mecanismo de transporte, lide da terra e defesa do território, passando a objeto da cavalaria medieval e da caça à raposa. Nesse ínterim, a esportivização das atividades hípicas faz surgir o hipismo e as mulheres vão conquistando outros e novos espaços no interior dos esportes hípicos.

\section{0 cavalo e as mulheres na Antiguidade}

A esse animal esbelto, respeitável e de grande porte coube a funcionalidade guerreira e a exibição de força e poder em campos de batalha na Antiguidade. Sua utilização foi largamente depreendida pelos hititas que, quando frente a uma tribo que não dispunha desse instrumento, garantiam a vitória. Os hunos, que fizeram dos cavalos uma extensão de seu corpo, obtiveram grandes vantagens em batalhas contra exércitos rivais, em especial os romanos. Em geral, acreditava-se que, apenas em posse de um cavalo, o homem teria condições de percorrer as enormes distâncias entre reinos, 0 que contribuiu para a ampliação do contato entre as civilizações e auxiliou no controle de reinos muito extensos.

Além do emprego para fins de transporte humano e de cargas, para gregos e romanos, ser cavaleiro implicava prestígio social, econômico e político. Durante a Idade Média, além de conferir status social aos que dele se utilizavam para o lazer, a cavalaria era uma instituição dotada de honra e seguidora de códigos de conduta guerreiros, que regulavam não somente a arte da guerra como a vida pública. Já no século XVI, os cavalos, seres desconhecidos dos povos nativos americanos, foram fundamentais para a conquista dos colonizadores ibéricos, por seus efeitos amedrontador e intimidador, características tipicamente associadas ao masculino. Nesse momento histórico, a função da colonização pertencia exclusivamente aos homens e aos seus cavalos. 
Desde o surgimento dos primeiros agrupamentos humanos, as atuações masculinas e femininas, que ainda hoje permeiam nossa sociedade, estavam muito bem delineadas. Tanto nas civilizações orientais como nas ocidentais, as atuações delas giravam em torno da dádiva da maternidade e das lides domésticas. As únicas referências de mulheres que desconheciam o retraimento e podiam exercer livremente a vida pública, inclusive desfrutando das mesmas práticas corporais masculinas, são da civilização Etrusca. Elas conheciam os desportos hípicos, bem como outras práticas, como qualquer homem. Hititas e cretenses também tiveram suas representantes do sexo feminino na equitação e em acrobacias realizadas por casais sobre quadrúpedes respectivamente.

A arte de montar a cavalo, entretanto, em grande parte dos povos antigos, foi exclusiva dos homens. Das poucas referências às mulheres que montavam cavalos, as mais significativas são as das guerreiras gregas "amazonas". Desobedientes e desregradas, elas desafiaram as "leis naturais" que delimitavam suas atuações sociais e sexuais e transgrediram os valores femininos vigentes na Antiguidade ao dominar, subjugar e banir os homens de sua estrutura política e social. Andavam a cavalo com as pernas afastadas, algo totalmente inescrupuloso para as mulheres da época. Mitologicamente é descrita como apreciadora da cultura física, da solidão, da vida ao ar livre e do trato dos animais, possuidora de um estilo de vida alternativo ligado ao amor entre as mulheres (SOUZA, 2012). A elas se deve também o desenvolvimento da Ilha de Lesbos, local que, devido à forte expressão da homoafetividade feminina, deu origem ao termo "lesbiandade". O emprego da palavra "amazona" hoje não mais remonta às práticas e concepções das fundadoras de Lesbos, mas designa meninas e mulheres que montam cavalos ou que praticam hipismo, sendo, portanto, o feminino de "cavaleiro".

Já a mulher ateniense devia comportar-se de forma submissa e reclusa, cerceada da vida política, social e esportiva. Podiam participar indiretamente dos Jogos Olímpicos como proprietárias de cavalos e/ou quádrigas, o que requeria certa abastança. Sobre

Movimento, Porto Alegre, v. 20, n. 3, p. 1197-1222, jul./set. de 2014. 
isso, vale ressaltar que a primeira mulher a ganhar uma medalha de ouro nos Jogos e a ter seu nome escrito no rol de "heróis" olímpicos foi a princesa espartana Kyniska, criadora dos cavalos de raça vencedores dos Jogos de 396 a.C. e 392 a.C. (MIRAGAYA, 2002, 2007).

É interessante notar que as primeiras mulheres atletas vieram de Esparta. Isso porque as mulheres que se exercitavam eram mais fortes e ágeis e os espartanos acreditavam que essas qualidades eram passadas à prole. Pode parecer que esses povos viam a figura feminina, em suas sociedades, de forma emancipada, no entanto, os espartanos estavam apenas imprimindo à atividade física um olhar eugênico, um meio no qual a maternidade era o fim. E, como os fins justificam os meios, a maternidade justificava a prática de atividades físicas pelas mulheres espartanas. Formas diferentes de ver a mesma situação: a vida da mulher em torno do cuidado do lar e dos filhos.

\section{0 cavalo-ATLetA}

O hipismo é descrito por Pereira e Mazo (2010) como possuidor de dupla origem. Além de ter primórdios nas práticas militares já elucidadas, também encontra ascendência nas atividades praticadas nas horas de lazer da aristocracia europeia da Baixa Idade Média e Idade Moderna. Na Inglaterra, a caça à raposa foi uma atividade apreciada por homens e mulheres, na qual os cavalos precisavam saltar troncos, riachos, barrancos e outros obstáculos naturais encontrados pelas florestas em busca do pequeno mamífero.

Grande desvantagem era imposta às caçadoras, que, segundo Adelman (2006), eram obrigadas a montar com as duas pernas para o mesmo lado da sela. O desenvolvimento dessa atividade estimulou a criação das primeiras pistas com obstáculos exclusivamente para o aperfeiçoamento dos saltos, constituindo-se em um legado para as modalidades Concurso Completo de Equitação (CCE) e Saltos do hipismo (VIEIRA; FREITAS, 2007). 
Atualmente subdividido em oito modalidades, sendo três delas componentes do quadro Olímpico ${ }^{1}$, a saber, Saltos, Adestramento e CCE, o hipismo diferencia-se dos demais esportes por ser o único em que homem e animal formam um conjunto. Nos Saltos, o cavaleiro/a amazona precisa superar de 12 a 15 obstáculos de variados tipos, alturas e distâncias, espalhados por uma pista de 700 a 900 metros. No adestramento, o cavaleiro/a amazona precisa executar alguns movimentos obrigatórios dentro de um espaço de tempo estabelecido, em uma área de 60 metros de comprimento por 20 metros de largura. Já no Concurso Completo de Equitação (CCE), os cavaleiros e as amazonas participam de provas de Saltos, adestramento e cross country ${ }^{2}$ ao longo de três dias de disputas.

O esporte possui, como linha básica para a boa performance, a total interação entre o cavalo e o cavaleiro/a amazona. Com o aprimoramento das técnicas de montaria, o comportamento do(a) cavaleiro/amazona passou a ser de facilitador do trabalho do animal. Inicialmente o montador ficava com o corpo na vertical, forçando seu equilíbrio nas rédeas e nos estribos no momento do salto. No final do século XIX, o italiano Frederico Caprilli, considerado o pai da equitação moderna, inovou ao inclinar o corpo para frente deixando o assento ligeiramente fora da sela, de forma que suas mãos acompanhavam o movimento do pescoço do animal em todas as fases do salto. Essa técnica foi nomeada "posição esporte" e é utilizada até hoje nas provas de Saltos (CONFEDERAÇÃO BRASILEIRA DE HIPISMO, 2012).

Muitos atletas, influenciados pelas escolas europeias, avaliam que o bom desempenho, na prova, depende, em medidas iguais, do bem estar, da qualidade técnica e da confiança mútua dos elementos do conjunto, em uma proporção de $50 \%$ para ambos. Essa proporção é exemplificada pelo único conjunto a conquistar três medalhas de ouro na história dos Jogos Olímpicos: o cavaleiro alemão Hans Günter Winkler e a égua Halla, campeões nas categorias individual

\footnotetext{
${ }^{1}$ Uma quarta, denominada especial, pertence ao quadro de modalidades Paraolímpicas.

${ }^{2}$ Consiste em um circuito montado com características e obstáculos naturais.
}

Movimento, Porto Alegre, v. 20, n. 3, p. 1197-1222, jul./set. de 2014. 
e por equipes em 1956 na Suécia, e novamente em 1960 na Itália, na categoria por equipes (COI, 2013; VIEIRA; FREITAS, 2007).

Outra característica exclusiva do hipismo no contexto dos esportes olímpicos é a ausência de categorias separadas por sexo, sendo o único em que formalmente homens e mulheres competem em formato de igualdade. Diferentemente de outros esportes, entende-se que a maior força física masculina não influencia no resultado do conjunto, o que explica essa peculiaridade do esporte. Esse elemento por si só mexe com a estrutura das competições, bem como com o emocional do desportista hípico. E percebendo que, ao falar de emoção no esporte tangenciamos questões de gênero, avistamos, nos equinos, percursos e obstáculos um potencial riquíssimo a se explorar sob o viés dessa problemática.

\section{Conceituando gênero}

Compreendemos o conceito de gênero à luz de Scott (1995, p. 75), como "[...] uma forma de indicar "construções culturais" a criação inteiramente social de ideias sobre os papéis adequados aos homens e às mulheres [...]". Longe de se resumir às opções sexuais, o conceito de gênero possibilita identificar como homens ou mulheres compartilham e entendem o que é ser homem ou mulher, ou seja, as formas de exercer as masculinidades ou feminilidades. Nessa esteira, o termo sobre o qual nos debruçamos é entendido como "uma categoria social imposta sobre um corpo sexuado. [...]" (SCOTT, 1995, p. 75). Gênero "tornou-se uma palavra particularmente útil, pois oferece um meio de distinguir a prática sexual dos papéis sexuais atribuídos às mulheres e aos homens".

No âmbito da Educação Física, Goellner(2007) e Devide et al. (2011) manifestam a importância dos estudos de gênero nessa área por percebê-los como uma categoria analítica, sendo seu conceito fundamental para compreender os processos internos das tramas de poder, nos quais as diferenças biológicas são tomadas para explicar a ocorrência de desigualdades sociais e de gênero, fomentando a

Movimento, Porto Alegre, v. 20, n. 3, p. 1197-1222, jul./set. de 2014. 
inclusão e a exclusão de sujeitos e grupos. Romero (2005) articula esses processos ao fato de as relações de gênero conferirem a homens e mulheres comportamentos diferenciados, evidenciando uma representação estereotipada e construída historicamente em meio às tramas sócio-históricas e culturais.

Para os termos masculinidades e feminilidades, encontramos guarida em, Paulson (2002) e Sabo (2002), que as definem como as diversas formas de ser homem ou ser mulher em determinada sociedade. Essas formas, vale destacar, estão imbricadas em relações de poder enaltecendo identidades "dominantes" e silenciando as "subalternas". Sob essa égide, a "masculinidade hegemônica" descrita por Connell (1995), Sabo (2002) e Seffner (2003) refere-se àquela predominante e dominante, a mais lisonjeada, idealizada e valorizada atuação social para o homem e, a "feminilidade enfatizada", como aquela que concebe o ideal cultural mais celebrado para mulheres em dado momento histórico (SABO, 2002; PAULSON, 2002).

Ambos os conceitos estão ancorados na dicotomia sexual, na polarização homem e mulher, e qualquer dissidência a esse aspecto heteronormativo é considerado anormal, transgressor, desviante, sendo fadada a punições. O determinismo biológico foi, por anos, chave para explicar as relações sociais e de poder. Segundo Paulson (2002) e Romero (2005), as diferenças sexuais foram pretexto para impor relações desiguais entre os sexos, limitar as possibilidades de vida, de manifestações de comportamento e, até mesmo, de atividades físicas, sociais e políticas.

Bourdieu (2012, p.8) aclara que esses conceitos são mecanismos históricos des-historicizados pela eternização das estruturas da divisão sexual, ou seja, ocorreu uma "transformação da história em natureza, do arbitrário cultural em natural”. Dessa forma, tais considerações, que ainda estão presentes em nossa sociedade, mantêm-se vivas por serem entendidas como parte inata da essência humana, não se fazendo possível definir quando foram instituídas, perdendo-se no tempo e no espaço e confundindo-se com a própria história da humanidade.

Movimento, Porto Alegre, v. 20, n. 3, p. 1197-1222, jul./set. de 2014. 


\section{Do LAR ÀS PISTAS, TRANSPONDO OBSTÁCULOS.}

O desprestígio da mulher nos desportos começa a regredir na Idade Média quando, conforme Oliveira, Cherem e Tubino (2008), elas tomam parte das mesmas atividades físicas que os homens. Entretanto, com o advento do regime vitoriano oriundo da Inglaterra do século XVII, profundas mudanças na sociedade redirecionam a mulher ao interior da domesticidade, subjugada social e economicamente ao marido. Isso acabou excluindo novamente a mulher das práticas corporais (OLIVEIRA, CHEREM; TUBINO, 2008).

Somente entre o final do século XVIII e início do XIX é que começa a haver uma reformulação nos ideários ingleses e os nobres cavalheiros passam a levar suas damas aos hipódromos, às competições de boxe e de remo, retomando seu acesso aos esportes. Timidamente a mulher começa a engatinhar no universo desportivo masculino (OLIVEIRA, CHEREM; TUBINO, 2008), e não demorou muito desde esses primeiros passos até sua inserção nos Jogos Olímpicos Modernos.

Reestabelecidos por Pierre de Coubertin em 1896, além de a sua realização ser mantida em Atenas, os Jogos Olímpicos conservaram a tradição grega de não inclusão das mulheres. Educado sob a influência do último período vitoriano, Coubertin entendia que a mulher era fisicamente frágil, meiga, gentil, submissa ao homem em todos os aspectos, sendo restrita, assim, à vida privada. Considerava os Jogos um lugar propício para enaltecimento da competitividade, força, virilidade e coragem, aspectos que, no seu entender, representavam unicamente a figura masculina exemplar (MIRAGAYA, 2007; OLIVEIRA; CHEREM; TUBINO, 2008). Coube a elas apenas a participação como espectadoras ou no pódio, coroando os atletas vencedores, mas desta vez não mais como os próprios prêmios.

Quatro anos depois, nos Jogos de Paris, problemas na organização e controle dos inscritos e a desarticulação do Comitê

Movimento, Porto Alegre, v. 20, n. 3, p. 1197-1222, jul./set. de 2014. 
Sob rédeas curtas, de cabelos longos ...

Olímpico Internacional (COI) foram fatores que acabaram por "permitir" a entrada de mulheres em algumas modalidades como golfe, vela e tênis, esportes destituídos de contato físico. A partir daí, a cada nova edição, mais modalidades recebiam a participação delas, que foram crescendo em número e em espaço dentro das competições, inicialmente apenas em esportes individuais e, a partir de 1924, adentrando nos desportos de combate através da esgrima.

Em 1896, o hipismo já fazia parte do programa olímpico como esporte de demonstração, mas somente em 1912, em Estocolmo, foi incorporado definitivamente aos Jogos (VIEIRA; FREITAS, 2007). Dominado até a década de 40 pela Alemanha nazista em todas as provas, ainda era uma prática essencialmente masculina, tendo os militares nas melhores colocações. Posteriormente, foram os Estados Unidos que começaram a apresentar grandes nomes ao mundo, particularmente após a criação de uma escola própria que, no início de suas atividades, atendeu majoritariamente a militares.

Sobre essa militarização inicial, Goellner (2005) comenta que o cavalo sempre foi uma paixão antiga da oligarquia, identificada com a elegância das elites europeias. Isso porque o custo elevado de manutenção do animal o afastava da população de civis de renda baixa e o tornava quase que exclusivo dos nobres e dos cavaleiros dos exércitos, limitando-se, assim, o acesso às práticas equestres. Nas instituições militares, o trato do cavalo era rotineiro e objetivava tornar o desempenho na montaria o melhor possível para atuação em eventuais batalhas e cerimônias (GOELLNER, 2005).

Bastos (2008) descreve que a carreira militar, desde seu surgimento na história, é um "gueto masculino", um "mundo de homens administrado por homens" (ALVESSON; BILLING, 1997 apud BASTOS, 2008, p.12). A função da mulher dentro dessas organizações era essencialmente de ordem administrativa subordinada, de enfermagem e de relações públicas. Além disso, passavam grandes dificuldades para ascender na carreira, pois os

Movimento, Porto Alegre, v. 20, n. 3, p. 1197-1222, jul./set. de 2014. 
postos de hierarquia superior eram vedados a elas, e a estes se inclui a Cavalaria. No Brasil, a primeira campanha feminina em guerra só se deu em 1820, com Maria Quitéria de Jesus que, disfarçada de soldado, lutou ao lado das tropas brasileiras. Ela, porém, só veio a ser reconhecida como a "Heroína da Independência do Brasil" mais de um século depois, em 1996 (FÁZIO, 2003 apud BASTOS, 2008, p.15).

De forma análoga, também era e ainda “é raro as mulheres ocuparem posições que permitam a tomada de decisão no esporte brasileiro", ou seja, na presidência de seus espaços organizacionais (MOURÃO; GOMES, 2004,p.308). Tais considerações comprovam a difícil trajetória das mulheres em um reduto por nós entendido como semelhante ao esporte no que se refere a sua finalidade: uma criação dos homens voltada para os homens (SABO, 2002).

Voltando nossos olhares para as ferraduras, botas, e longas madeixas, Rojo (2007c) elucida que a presença feminina no hipismo brasileiro é registrada desde meados do século $\mathrm{XX}$, com Candinha Prates, filha do primeiro presidente da Sociedade Hípica Paulista. Ela partilhou de um reduto majoritariamente militar e, portanto, masculino, nunca chegando a integrar a equipe olímpica brasileira de hipismo, que estreou nos Jogos Olímpicos em 1948, em Londres. Esse quadro só começa a mudar a partir da década de 60 , na qual gradativamente os civis adentram o universo hípico, estando nesse estrato incluídas as mulheres. Ainda segundo Rojo, a primeira mulher a integrar, em 1968, a equipe olímpica brasileira de hipismo foi Lúcia Faria Alegria Simões, que acabou em $7^{\circ}$ lugar na competição por equipes e em $12^{\circ}$ na disputa individual (CONFEDERAÇÃO BRASILEIRA DE HIPISMO, 2012, 2013).

Segundo informações do COI, a estreia feminina no hipismo olímpico só ocorreu em 1952, com Ida Von Nagel, da Alemanha, conquistando a medalha de bronze no Adestramento por Equipes e Lis Hartel, da Dinamarca, ficando em segundo no Adestramento Individual. Esta última, superando todas as dificuldades impostas pela poliomielite contraída aos 23 anos, não abandonou as pistas e,

Movimento, Porto Alegre, v. 20, n. 3, p. 1197-1222, jul./set. de 2014. 
aos 31 anos, representou seu país nas Olimpíadas, mesmo tendo de ser assistida para montar a cavalo.

Em 1956, nas Olimpíadas de Melbourne, a inglesa Patricia Rosemary Smythe fica com o bronze nos Saltos. Neste mesmo ano, os EUA inovam ao apresentar uma equipe totalmente feminina no Adestramento, terminando com a segunda colocação geral da categoria. Liselott Linsenhoff, que integrou a equipe norte-americana, conquistou ainda o terceiro lugar no Individual, perdendo para a dinamarquesa Lis Hartel, segunda colocada.

Em 1964, outra dinamarquesa, Marianne Gossweiler, fica com a prata no Adestramento por Equipes, mas não repete o feito em 1968, perdendo para a equipe da URSS de Elena Petushkova, que levou a prata. A francesa Janou Lefevre e a inglesa Marion Janice Coakes incrementam o quadro de medalhas femininas nos Saltos angariando, respectivamente, duas pratas nos Saltos por Equipes (1964 e 1968) e uma prata no Salto Individual (1968). A partir daí, gradualmente, as participações femininas só aumentaram, sobretudo, no Adestramento.

O resultado preliminar da análise das participações femininas de 1952 a 1968 já nos permite atentar que as mulheres, apesar de sua inserção tardia, sobressaíram na modalidade Adestramento. Em meados da década de 50, a presença de duas amazonas entre os três primeiros colocados no Adestramento Individual causou receio nos cavaleiros, que temiam que as mulheres, há pouco ingressas no esporte, sobressaíssem e arrebatassem sua hegemonia. Segundo a atleta Pat Smythe, em seu livro autobiográfico citado por Rojo (2008), eles chegaram a propor e introduzir competições exclusivas para senhoras, como forma de proteger seus próprios campeonatos.

Nos Saltos, além da menor quantidade de participantes, elas obtiveram menor quantidade de medalhas olímpicas. Outro fato curioso é que, durante o período elencado, inexistiram conquistas femininas no Concurso Completo de Equitação (CCE), justamente na modalidade que apresenta risco de queda e de lesões

Movimento, Porto Alegre, v. 20, n. 3, p. 1197-1222, jul./set. de 2014. 
permanentes superior às demais. Entretanto, afirmar que o perigo de uma modalidade é o fator de maior peso para o afastamento das mulheres de sua prática é asseverar que estão mais dispostas a sofrer os danos recorrentes dos esportes do que os homens, ou que elas são mais temerosas do que eles, e estaríamos indo ao encontro dos estereótipos e dos preconceitos já ultrapassados envolvendo a participação feminina nas atividades corporais.

\section{Essas mulheres... Esses cavalos... Por trás das COCHEIRAS.}

Apesar de não ter realizado uma pesquisa de campo, Rojo (2007a, 2007b, 2007c, 2008, 2010, 2011), Adelman (2003, 2006, 2011) Adelman e Moraes (2008), Pereira e Mazo (2010) e Pereira, Silva e Mazo (2011) apresentam uma gama de interpretações iniciais que poderão vir a delinear os caminhos a serem perseguidos em iniciativas próximas.

As principais inferências em torno dos dados dessas pesquisas apontam para uma hierarquização das modalidades hípicas. O Salto, além de ter um público espectador maior, é descrito como uma atividade que demanda coragem e raça. Já o Adestramento, considerado por alguns atletas como a essência da equitação e, por outros, "coisa de fresco" (Rojo, 2007a) ou "a irmã puta" dos Saltos (Rojo, 2008; 2010), é descrito por sua plasticidade e harmonia entre o cavalo e o cavaleiro/a amazona, sendo necessária a sensibilidade do atleta para sentir o animal e fazê-lo mostrar toda a sua elegância. Por suas especificidades, dentre elas a possibilidade de realizar a prova com acompanhamento musical, o Adestramento é associado às danças: uma espécie de ballet a cavalo. Essa associação é um forte indício para explicar o uso do tom jocoso para designá-lo.

A indistinção de categorias por sexo não conseguiu eximir o hipismo das desigualdades de gênero, tendo no elemento emoção um forte marcador das identidades masculinas e femininas. Há a presunção, por parte dos atletas, de que "os homens são naturalmente mais corajosos" e "as mulheres são naturalmente

Movimento, Porto Alegre, v. 20, n. 3, p. 1197-1222, jul./set. de 2014. 
Sob rédeas curtas, de cabelos longos ...

mais sensíveis" (ROJO, 2007a, p. 83), ficando clara uma hierarquização das modalidades segundo o sexo: Saltos para rapazes e Adestramento para moças. No entanto, a presença de feminilidades e masculinidades "outras" repaginam a conformação dos gêneros no hipismo, através da presença de mulheres corajosas e homens sensíveis, dissidentes do estereótipo de masculino e feminino que a sociedade hípica tem para esses atletas.

Essa inversão de emoções "masculiniza" mulheres, que passam a rivalizar com homens e "feminiza" homens, que adentram um dos poucos espaços esportivos dominado pelas mulheres. Em uma das experiências que marcou a trajetória hípica da autoria, uma prova de endurance equestre ${ }^{3}$ no interior de Brasília, um rapaz de 16 anos elogia sua equitação da seguinte forma: "Nunca vi uma mulher montar como você. Não tem medo algum do cavalo. A maioria das meninas foge ou, quando querem montar, pedem que as coloque na sela. Então você chega e ganha de nós...". Percebemos, nesse discurso como naquele contexto hípico, que a visão que se tem da mulher envolve o temor à figura do cavalo, para além da inabilidade ou inaptidão ao desafio com os cavaleiros. Logo, a autoria pôde inferir que, naquele grupo social de equitadores, as mulheres que montam cavalos tão bem quanto, ou melhor que os homens, não se enquadram nas representações mais vislumbradas e celebradas para a feminilidade. Vale lembrar que essas representações de feminilidades (e masculinidades) mudam de acordo com o contexto social, histórico e cultural de cada grupo.

Rojo (2007b), sob a luz de Gallissot (1987) e Vale de Almeida (1995), em uma interessante comparação entre o contexto hípico uruguaio e o carioca, elucida que não há uma identidade feminina homogênea e universalizada para o grupo social hípico. Essas identidades pertencem a um contexto social maior, no qual determinado grupo hípico está inserido, só sendo percebida e entendida quando olhamos para essa sociedade de modo geral e percebemos suas intrínsecas relações de poder. Dessa forma, Rojo ${ }^{3}$ Prova não olímpica, porém uma das oito regulamentadas pela Federação Equestre Internacional. Trata-
se de uma corrida de longa distância que pode chegar até a 160 quilômetros em sua versão mais longa.

Movimento, Porto Alegre, v. 20, n. 3, p. 1197-1222, jul./set. de 2014. 
(2007b) pôde perceber que as mulheres em Montevidéu, devido a sua educação para a domesticidade, abandonam totalmente o universo hípico quando se deparam com o casamento e a maternidade, não havendo dissidências nesse comportamento.

No âmbito social brasileiro, Adelman (2006) verifica que, nos Saltos, à medida que a altura dos obstáculos aumenta, diminui-se a quantidade de mulheres competindo, pois muitas abandonam o esporte para dedicarem-se à maternidade, da qual não abrem mão, apesar do contragosto em abandonar seus projetos esportivos profissionais. Essa evasão feminina é explicada pelo aconselhamento da medicina de cessar as atividades equestres durante a gravidez, devido ao alto risco de quedas. Sabendo que as categorias dessa modalidade são uma combinação entre idade dos atletas e altura dos obstáculos, a opção por constituir uma família dificulta o acesso e/ou permanência das mulheres nas categorias elevadas. Entretanto, Rojo (2007b) constatou a existência de mulheres que renunciam à maternidade para desfrutar das glórias do esporte sem impedimentos, enquanto outras ainda "dão um jeitinho", coincidindo a gravidez com o calendário de competições.

O casamento e a gravidez limitam as possibilidades da mulher atleta, seja pelo tempo em que precisarão ficar distantes das pistas, seja pela impossibilidade de viajarem para competições em decorrência dos cuidados com as crianças pequenas. Essa necessidade de escolher entre ser atleta ou exercer a feminilidade é, no contexto hípico, um empecilho ao atleticismo feminino, comprovando como estes ainda são elementos de difícil articulação. Percebe-se que, tanto para a mulher brasileira quanto para a uruguaia, o esporte e a feminilidade precisam ser vividos em separado, ainda que temporariamente.

O Adestramento, indo de encontro a toda organização da instituição esportiva que se conhece, é uma modalidade majoritariamente praticada e dirigida por mulheres. Discursos que remontam à emotividade feminina e à necessidade dessa 
modalidade de um maior entrosamento entre cavalo e o cavaleiro/a amazona são mais uma prova de que o determinismo biológico ainda persiste na tentativa de justificar sua ascendência em uma modalidade desportiva, como se as mulheres não tivessem a real capacidade de despontar no campo historicamente dominado por homens que é o esporte.

Rojo (2007c) identifica que a postura dos treinadores por modalidade no ambiente competitivo também diverge. A competitividade aflorada influencia no tratamento destinado pelo treinador de Saltos aos atletas, sejam estes homens sejam mulheres, estando mais próximos dos estereótipos masculinos: dirigem-se aos atletas utilizando postura de desqualificação quando erram ou adotam uma postura grosseira ou rude quando desacatam uma instrução. O oposto ocorre quando se trata da relação treinadoratleta da modalidade Adestramento: por ser uma modalidade menos dinâmica e que demanda concentração por parte do atleta, o tom das conversas é mais suave e baixo (ROJO, 2007c).

A vivência prática da autoria na modalidade Saltos comprova essa afirmação de Rojo (2007c): é comum, durante os treinos, quando a amazona não está se saindo como o esperado pelo treinador, que este se utilize de censuras tais como: "Você veio pra cá pra saltar ou o quê? Senão, pode ir para casa brincar de boneca ou de cozinha!". Percebe-se, nessa assertiva do instrutor, clara distinção entre o modelo hegemônico de feminilidade e o mais adequado ao ambiente hípico. O uso dos símbolos ditos femininos "boneca" e "cozinha", mais do que polarizar as feminilidades apropriadas e não apropriadas ao hipismo, denota o quanto esse ambiente de rivalidade entre homens e mulheres impõe a ambos um tratamento generificador. Para os cavaleiros, as repreensões também estão ligadas à construção de uma masculinidade ajustada ao esporte: "Hoje você vai montar este cavalo, para vermos como o conjunto se sai. Ou vai me dizer que você tem medo de cavalo?". O medo, portanto, não é um atributo da masculinidade que o hipismo arquiteta, bem como não é da masculinidade hegemônica. 
Com relação à competitividade, ao possibilitar a rixa entre adversários de sexos diferentes, o hipismo afigura-se como um espaço em que os homens de fato provam e põem à prova sua masculinidade. Eles enaltecem-se por terem a coragem de se lançar a alturas maiores nos obstáculos, de forma que a derrota para uma mulher nos Saltos constituiria um vexame, vergonha e desonra para o homem. Isso já caracteriza a modalidade como um reduto de sobrevalorização masculina e subjugação feminina, as quais vêm sendo historicamente perpetuadas. Basta atentarmos para as composições e conquistas mais recentes da equipe olímpica brasileira: em 1996 e 2000, conquistou o terceiro lugar nos Saltos por equipe, e em 2004, com Rodrigo Pessoa, o Brasil ficou com a primeira colocação no Individual. No contexto equestre brasileiro, mulheres nunca ganharam medalhas olímpicas (COI, 2013).

Entrementes, há uma hierarquização das conquistas segundo o gênero. Nos Saltos, vencer a mulher torna-se uma necessidade, devido às características masculinizadas da modalidade. O Adestramento já aparece para as mulheres, majoritárias nas provas, como uma forma de obtenção de espaço e prestígio no esporte. Portanto, não é qualquer vitória que interessa ao homem, uma vez que a imposição da virilidade se dá pela vitória sobre a mulher e outros homens em seu território de domínio: o terreno da masculinidade. Destarte, o reconhecimento esportivo feminino se dá pela vitória apenas onde lhe é cabida, a fim de não pôr em xeque a feminilidade da atleta.

O estudo de Adelman (2011) demonstrou que, cada vez, mais mulheres estão requerendo seu espaço nas hípicas. Hoje já comparecem em iguais proporções frente aos homens no hipismo de Salto, a despeito do privilégio conferido a estes, do universo de homossociabilidade masculina das hípicas e de sua associação com as atividades militares de outrora. A diminuição do quantitativo fardado em competições equestres também é relatada por Adelman (2011) e refletida na redução do domínio militar nesse esporte. Assim como a militarização do hipismo foi uma questão histórica, a masculinização dos Saltos também se afigura como uma questão de tempo.

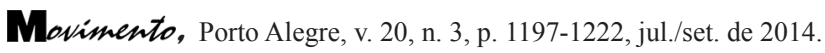




\section{Considerações finais}

Finalizando o percurso deste empreendimento, consideramos útil ilustrar o efeito cascata que delineia a inserção feminina nas práticas hípicas: em um primeiro momento, era o cavalo visto como mecanismo de transporte, lide da terra e defesa do território. Posteriormente, as atividades da cavalaria medieval e a caça à raposa na Inglaterra instituem um novo olhar sobre este animal e a esportivização das atividades hípicas faz surgir o hipismo, sobretudo, dentre o meio militar. As mulheres inicialmente espectadoras, vão, pouco a pouco, adentrando as cocheiras, dominando suas montarias, os pódios e os Jogos Olímpicos.

Apesar da desmilitarização e da entrada da mulher no hipismo, a visibilidade midiática da amazona é ínfima. Isso porque os interesses da mídia estão atrelados ao enaltecimento de formas corporais sensuais, pouco importando seu desempenho esportivo. Explicitamos que frequentemente a atleta é exposta em poses que objetivam vender sua beleza a um público majoritariamente masculino. No hipismo, os trajes utilizados impossibilitam que o apelo à sensualidade das formas femininas seja depreendido pela imprensa, pois a vestimenta delas assemelha-se à dos homens. Essa indistinção nas roupas seria um indicativo de que o esporte não faz distinção entre os atletas, no entanto, impor à mulher a mesma indumentária que a dos homens abre precedentes para que se questione que tipo de gênero o hipismo valoriza e quais ele deprecia. O vestiário por demais recatado, atrelado ao público alvo reduzido, uma vez que o hipismo é considerado um esporte inatingível a uma parcela significativa da população, resulta em uma cobertura midiática ínfima, restrita aos grandes eventos internacionais como Jogos Olímpicos e Pan-americanos, e ainda assim, quando televisionado, sua exibição não ocorre em canais abertos.

Inferimos que mulheres e cavalos já foram, e ainda são, objetos de desejo de alguns homens. Em várias sociedades e culturas, antigas e atuais, ser proprietário de cavalos é indicativo

Movimento, Porto Alegre, v. 20, n. 3, p. 1197-1222, jul./set. de 2014. 
de riqueza. Domesticar e dominar um animal como este concede poder a quem o monta, ainda que um poder ideológico. Até hoje, há homens que praticam e admiram as práticas equestres não por gostarem de cavalos, mas por apreciarem a demonstração pública de coragem, força e altivez que é fazer obedecer a um cavalo, sendo essa a identidade de gênero hegemonicamente aceita para eles. Porém, mais do que à própra idendidade de gênero, esses atributos estão relacionados ao que Connell (1997) apud Fialho (2006) e Seffner (2003) chamam de masculinidade hegemônica. Vencer uma prova hípica é, nessa esteira, a expressão máxima de sua superioridade e autoexaltação, tanto frente às mulheres quanto a outros homens.

Os autores Curado e Curado (2005) delatam o significado simbólico do cavalo, o qual, para homens, é considerado signo da potência e do desempenho sexual e, para as mulheres, interpretado como manifestação de seu desejo sexual. Dessa forma, consideramos que, para o grupo social hípico, a mulher a cavalo figura como um alvo a ser conquistado pelo masculino, e o homem a cavalo, como o objeto de desejo do feminino. Para além desses signos, os desafios e riscos impostos pela modalidade fazem a imagem convencional de sexo frágil atrelada ao feminino passar longe da mulher amazona, fazendo-nos depreender que esta é uma identidade de gênero que, apesar de não ser fixa e não caracterizar todas as praticantes, distancia-se da feminilidade enfatizada.

Mas, quem disse que só são sensuais as mulheres que se enquadram no padrão enfatizado? O erotismo ao corpo feminino a cavalo, ainda que não perpetuado pela mídia, é de conhecimento do grupo social hípico, embora seu conceito divirja de acordo com o contexto societário. Tal consideração é elucidada ao trazermos à tona o motivo que afastava as mulheres das práticas equestres no início do século XX: quando não pertencentes às famílias nobres, para quem as práticas equestres eram comuns nos momentos de lazer, aquelas que demonstrassem apreço por montar eram vistas como prostitutas.

Movimento, Porto Alegre, v. 20, n. 3, p. 1197-1222, jul./set. de 2014. 
Por fim, constatamos que o cavalo não apenas serve como elemento diferenciador das relações entre homens e mulheres, como também de inúmeras identidades de gênero inseridas nas práticas equestres. $\mathrm{O}$ hipismo, ainda que se exima formalmente da reprodução de diferenças entre os sexos, atua na (re)construção de novas relações e desigualdades de gêneros.

Após este intenso percurso, percebemos que os pesquisadores da Educação Física e Esporte não se familiarizaram ainda com o tema sobre esportes olímpicos não convencionais, quiçá quando se trate de inseri-los nos estudos de gênero. Dito isso, sentimos a necessidade de a área da Educação Física e Esporte se apoderar da temática "gênero" nos estudos que contemplem essas modalidades, uma vez que configuram uma lacuna nesse campo. 
Under a tight rein, with long hair: reflections about women in Equestrian sports.

Abstract: This descriptive review aims to reflect on inclusion and permanence of women in equestrian sports, starting a discussion focused on the social construction of femininities within an elitist modality and underexplored by the field of bodily practices. The literature discussed shows the existence of stereotyped visions directed to female athletes when the subject is competition, family and emotion. The horse personifies as a sign marker and differentiator of gender identities within equestrian practices, even though the modality exempts itself from inequality between sexes. Keywords: Equestrian sports. Women. Femininities. History.

Debajo de las riendas cortas, con el pelo largo: reflexiones sobre las mujeres en la equitación.

Resumen: Esta revisión descriptiva tiene como objetivo reflejar la inclusión y permanencia de las mujeres en la equitación, comenzando una discusión centrada en la construcción social de las feminidades en el contexto de una modalidad elitista y poco explorada por el campo de las prácticas corporales. La literatura discutida revela visiones estereotipadas dirigidas a mujeres atletas cuando el tema es la competición, la familia y la emoción. El caballo es personificado como un signo marcador y elemento diferenciador de las identidades de género insertadas en las prácticas ecuestres, aunque la modalidad se abstiene de la desigualdad entre los sexos.

Palabras clave: Equitación. Mujer. Feminidades. Historia. 


\section{REFERÊNCIAS}

ALDEMAN, Mirian. Mulheres atletas: transformações da corporeidade feminina? In: Reunião da ANPOCS, 23, 1999. Anais... Caxambu, 1999.

ALDEMAN, Mirian. Mulheres atletas: re-significações da corporalidade feminina?. Revista Estudos Feministas, Florianópolis, v.11, n.2, p.445-466, 2003.

ALDEMAN, Mirian. Mulheres no Esporte: Corporalidades e Subjetividades. Movimento, Porto Alegre, v.12, n. 1, p.11-29, 2006.

ALDEMAN, Mirian; M.; Moraes, F.A. Tomando as rédeas: um estudo etnográfico da participação feminina e das relações de gênero no turfe brasileiro. Esporte e Sociedade, Rio de Janeiro,v.3, p.1-29, 2008.

ALDEMAN, Mirian. As mulheres nos esportes equestres: forjando corporalidades e subjetividades «diferentes〉. Revista Estudos Feministas, Florianópolis, v.19, p.931-953, 2011.

BASTOS, M.L.C. Formação de identidade da mulher militar: análise do caso do Serviço de Saúde do Exército Brasileiro. Trabalho de Conclusão de Curso (Especialização) - Escola de Saúde do Exército, Programa de Pós-Graduação em Aplicações Complementares às Ciências Militares, 2009.

BOURDIEU, P. A dominação masculina. 11. ed. Rio de Janeiro: Bertrand Brasil, 2012.

COMITÉ OLÍMPICO INTERNACIONAL. Olympic.org: Official website of the Olympic Movement. Sports. Equestrian. Event Results: Dressage; Eventing; and Jumping. Disponível em: < http://www.olympic.org/>. Acesso em: 20 Jun. 2013.

CONFEDERAÇÃO BRASILEIRA DE HIPISMO. Histórico - Saltos. 2012. Disponível em: <http://www.cbh.org.br/historico-salto.html>. Acesso em: 20 Jun. 2013.

CONFEDERAÇÃO BRASILEIRA DE HIPISMO. Pelo segundo ano, Thiago Rhavy com Cordina JMen vence o mini GP Mitsubihsi no OiBHS em Mangaratiba. 2013. Disponível em: <http://www.cbh.org.br/noticias-geral/5632-pelo-segundoano-thiago-rhavy-com-cordina-jmen-vence-o-mini-gp-mitsubihsi-no-oibhs-emmangaratiba.html>. Acesso em: 20 Jun. 2013.

CONNELL, R. Políticas da masculinidade. Educação \& Realidade, Porto Alegre, v. 20, n.2, p.184-206, jul./dez, 1995.

CURADO, M.; CURADO, A.L. O cavalo e a jovem rapariga. In: COLÓQUIO DE ESTUDOS CLÁSSICOS, 2005. A Antiguidade Clássica e Nós: Herança e identidade Cultural. [Braga : Instituto de Letras e Ciências da Universidade do Minho, 2005?]. Disponível em: < http://repositorium.sdum.uminho.pt/ xmlui/bitstream/handle/1822/6772/Conferencia \%20CAVALO $\% 20$ JOVEM $\% 20$ RAPARIGA.pdf?sequence=1>. Acesso em: 14 Jan. 2014.

Movimento, Porto Alegre, v. 20, n. 3, p. 1197-1222, jul./set. de 2014. 
DEVIDE, F. et al. Estudos de gênero na Educação Física Brasileira. Motriz, Rio Claro, v. 17, n. 1, p. 93-103, jan./mar. 2011.

FERREIRA, M.E.M.P. A física moderna como instrumento da Educação: uma pesquisa de fenômeno situado. In: BICUDO, M.A.V.; ESPOSITO, V.H.C. Pesquisa qualitativa em educação: um enfoque fenomenológico. Piracicaba: Editora Unimep, 1994. p. 67-79.

FIALHO, F.M. Uma crítica ao conceito de masculinidade hegemônica. In: SEMINÁRIO INTERNACIONAL FAZENDO GÊNERO 7., 28- 30 de ago. 2006.. Anais..., Florianópolis: UFSC, 2006.

GOELLNER, S.V. Mulher e esporte no Brasil: entre incentivos e interdições elas fazem história. Pensar a Prática, Goiânia, v.8, n.1, 2005, p.85-100.

GOELLNER, S.V. História das mulheres no esporte: o gênero como categoria analítica. In: CONGRESSO BRASILEIRO DE CIÊNCIAS DO ESPORTE, 15 e CONGRESSO INTERNACIONAL DE CIÊNCIAS DO ESPORTE, 2., 2007. Anais... Recife: Colégio Brasileiro de Ciências do Esporte, 2007. v. 1, p. 1-10.

MIRAGAYA, A. A mulher olímpica: tradição versus inovação na busca pela inclusão. In: DA COSTA, L.P., TURINI, M. Coletânea de textos em estudos olímpicos. Rio de Janeiro: Gama Filho, 2002. v.1.

MIRAGAYA, A.. As mulheres nos Jogos Olímpicos: participação e inclusão social. In: RUBIO, Katia. Megaeventos esportivos, legado e responsabilidade social. São Paulo: Casa do Psicólogo, 2007. p.229-231.

MOURÃO, L. ; GOMES, E. M. P. Mulher na administração esportiva brasileira: uma trajetória em curso. In: SIMÕES, A.J.; KNIJNIK, J. D.. (Org.). O mundo psicossocial da mulher no esporte: comportamento, gênero e desempenho. São Paulo: Aleph, 2004. p. 305-318.

OLIVEIRA, G.; CHEREM, E.H.L.; TUBINO, M.J.G. A inserção histórica da mulher no esporte. Revista Brasileira de Ciência e Movimento, Brasília, v.2, n.16, p.117125, 2008.

PAULSON, S. Sexo e gênero através das culturas. In: ADELMAN, M.; SILVESTRIN, C.B. (Orgs.). Coletânea Gênero Plural. Curitiba: Ed. UFPR. 2002. p.254.

PEREIRA, E.L.; MAZO, J. Z. Salto alto e botas: representações das mulheres nas práticas equestres em Porto Alegre/RS produzidas pela Revista do Globo (1929-1967). In: SEMINÁRIO FAZENDO GÊNERO, 9. Diásporas, Diversidades, Deslocamentos. Florianópolis: UFSC, 2010. p. 1-10.

PEREIRA, E.L.; SILVA, C.F.; MAZO, J.Z. Revista do Globo: as mulheres portoalegrenses nas práticas equestres. Motriz, Rio Claro, v.17 n.2, p.292-302, 2011.

ROJO, L.F. Igualdade de sexo e desigualdade de género: relações entre homens e mulheres no hipismo. Omertaa (Kessel-Lo), Lovaina, Bélgica, v. 2, p.2, 2007. 
Sob rédeas curtas, de cabelos longos ...

ROJO, L.F. Relações de gênero no hipismo: um olhar comparativo entre Rio de Janeiro e Montevidéu. Artigo elaborado a partir da Exposição no curso de Antropologia. Universidad de La República. Montevidéu. 2007. Disponível em: < http://www.unesco.org.uy/shs/es/areas-de-trabajo/ciencias-sociales/publicaciones/ fileadmin/templates/shs/archivos/anuario2007/articulo_12.pdf>. Acesso em: 22 Out. 2013.

ROJO, L.F. Identidades de gênero: o hipismo e os discursos sobre igualdade sexual no esporte. In: REUNIÃO DE ANTROPOLOGIA DO MERCOSUL, 7., 2007. Anais... Porto Alegre: RAM, 2007.v.1, p.1.

ROJO, L.F. Masculinidades no contexto hípico uruguaio. In: ENCONTRO DA ASOCIACIÓN LATINOAMERICANA DE ESTUDIOS SOCIOCULTURALES DEL DEPORTE, 1., 2008. Esporte na América Latina: atualidade e perspectivas. Curitiba, 2008. p. 1-9.

ROJO, L.F. Borrando los sexos, creando los géneros: construcción de identidades de género en los deportes ecuestres en Montevideo y Rio de Janeiro. Vibrant, Florianópolis, v.6, p.50-71, 2010.

ROJO, L.F. A produção do gênero no hipismo à luz dos discursos sobre as emoções. In: COELHO, Maria Cláudia; REZENDE, Claudia Barcellos. (Org.). Cultura e sentimentos: ensaios em Antropologia das Emoções. Rio de Janeiro: Contra Capa, 2011. v.1, p.7-219.

ROMERO, E. E agora, vão fotografar o quê? As mulheres no esporte de alto rendimento. Labrys. Estudos Feministas (Online), Brasília, v. 8, p.1-29, 2005.

SABO, D. O estudo crítico das masculinidades. In: ADELMAN, M.; SILVESTRIN, C.B. (Orgs.) Coletânea Gênero Plural. Curitiba: Ed. UFPR. 2002. p.254.

SCOTT, Joan. Gênero: uma categoria útil de análise histórica. Educação e Realidade, Porto Alegre, v.20, n.2, p.71-99, jul/dez., 1995.

SEFFNER, F. Derivas da Masculinidade: representação, identidade e diferença no âmbito da masculinidade bissexual. Porto Alegre, 2003, 260 f. Tese (Doutorado em Educação) - Programa de Pós Graduação em Educação, Faculdade de Educação, Universidade Federal do Rio Grande do Sul, Porto Alegre, 2003.

SOUZA, I.S.F. de. O mito das Amazonas: uma discussão psicanalítica sobre a feminilidade. Maringá, 2012, 123f. Dissertação (mestrado) - Universidade Estadual de Maringá, Centro de Ciências Humanas, Letras e Artes, Programa de PósGraduação em Psicologia, Maringá, 2012.

VIEIRA, Silvia; FREITAS, Armando Freitas. O que é hipismo: História, regras, curiosidades. Rio de Janeiro: Casa da Palavra: COB, 2007.

Movimento, Porto Alegre, v. 20, n. 3, p. 1197-1222, jul./set. de 2014. 


\section{Ensaios}

Endereço para correspondência:

Vanessa Silva Pontes

Escola de Educação Física e Desportos

Universidade Federal do Rio de Janeiro

Avenida Carlos Chagas Filho, 540

Cidade Universitária

Rio de Janeiro,RJ

CEP: 21941-599

Brasil.

Recebido em:24.09.2013

Aprovado em: 31.05.2014

Movimento, Porto Alegre, v. 20, n. 3, p. 1197-1222, jul./set. de 2014. 